Running Head: COUNTER-STEREOTYPES

Some Extended Psychological Benefits of Challenging Social Stereotypes:

Decreased Dehumanization and a Reduced Reliance on Heuristic Thinking

\author{
Francesca Prati ${ }^{1}$, Milica Vasiljevic ${ }^{2}$, Richard J. Crisp ${ }^{3}$, \& Monica Rubini ${ }^{1}$ \\ ${ }^{1}$ Department of Psychology, University of Bologna, Italy \\ ${ }^{2}$ Behaviour and Health Research Unit, University of Cambridge, UK \\ ${ }^{3}$ Department of Psychology, University of Sheffield, UK
}

\begin{abstract}
Author note
Correspondence regarding this article should be sent to Francesca Prati at the University of Bologna, Department of Psychology, 5 Berti Pichat, 40126, Italy; phone number: 0039051 2091632; email: francesca.prati@unibo.it
\end{abstract}


Some Extended Psychological Benefits of Challenging Social Stereotypes:

Decreased Dehumanization and a Reduced Reliance on Heuristic Thinking

\begin{abstract}
One way to promote equality is to encourage people to generate counter-stereotypic rolemodels. In two experiments, we demonstrate that such interventions have much broader benefits than previously thought - reducing a reliance on heuristic thinking and decreasing tendencies to dehumanize outgroups. In Experiment 1, participants who thought about a gender counterstereotype (e.g., a female mechanic) demonstrated a generalized decrease in dehumanization towards a range of unrelated target groups (including asylum seekers and the homeless). In Experiment 2 we replicated these findings using alternative targets and measures of dehumanization. Furthermore, we found the effect was mediated by a reduced reliance on heuristic thinking. The findings suggest educational initiatives that aim to challenge social stereotypes may not only have societal benefits (generalized tolerance), but also tangible benefits for individuals (enhanced cognitive flexibility).
\end{abstract}

(Word count: 129)

Keywords: counter-stereotypes, prejudice, categorization, dehumanization, heuristics 


\section{Some Extended Psychological Benefits of Challenging Social Stereotypes: Decreased Dehumanization and a Reduced Reliance on Heuristic Thinking}

Stereotyping is one of the most persistent and pervasive problems of modern society (Eagly \& Mladinic, 1989; Glick \& Fiske, 2001; Jost \& Kay, 2005). Correspondingly, social psychological interventions have been developed to help challenge stereotyping in education and in industry (Blair, Ma, \& Lenton, 2001; Kawakami, Dovidio, \& Van Kamp, 2005). A particularly effective intervention involves encouraging individuals to genderate counter-stereotypic role-models (Beaman, Chattopadhyay, Duflo, Pande, \& Topalova, 2009; Dasgupta \& Asgari, 2004; Tidball, Smith, Tidball, \& Wolf-Wendel, 1999). In this research we investigated the extended benefits of interventions that employ counter-stereotypes. We argue that the value and effectiveness of these interventions might be much more expansive than previously thought. In particular, we test the idea that thinking about counter-stereotypes may have benefits that extend beyond the goal of promoting greater equality, to fostering enhanced cognitive flexibility and generalized tolerance towards a range of groups. In what follows, we first review the literature on counter-stereotypes, then go on to present our theoretical model of how exposure to counter-stereotypes may affect a particularly pernicious form of prejudice: the dehumanization of outgroups.

\section{Counter-Stereotypes Reduce Stereotyping}

Interventions that ask individuals to imagine a counter-stereotypic target (i.e., stereotypes of groups that do not typicality 'go together' such as a Gay Soldier or a Female Mechanic) have been found to reduce the negative impact of stereotypes in impression formation (Hastie, Schroeder, \& Weber, 1990; Hutter \& Crisp, 2005; 2006; Kunda, Miller, \& Claire, 1990). This happens because counter-stereotypes prompt a shift from a heuristic, categorical mode of impression formation, to a more generative, individuated mode of impression formation (Fiske \& Neuberg, 1990; see also Brewer, 1988). As such, after being encouraged to think about a target along new, stereotypically incongruous dimensions of categorization the conflicting information must be conceptually integrated, inconsistencies resolved, and a revised impression formed. For instance, Hutter and 
Crisp (2005) demonstrated that after thinking about gender counter-stereotypes (e.g., a "Female mechanic" or "Male nurse"), participants generated fewer constituent and more emergent (novel) attributes to describe the target. Hutter and Crisp argued that there are two distinct elements of inconsistency resolution in multiple category contexts: generative thought (reconstructing the target with individualized emergent attributes) and constituent disinheritance. Constituent disinheritance is the inhibition of stereotypic traits required to resolve the categorical inconsistency. If the target does not fit either constituent stereotype, those stereotypes must be, at least to an extent, discarded. Consistent with the idea that perceiving such counter-stereotypic combinations draws on processes outlined in Fiske and Neuberg's (1990) impression formation continuum, Hutter, Crisp, Humphreys, Waters, and Moffitt (2009) showed that perceivers appear to use categories at early stages of impression formation, but when the stereotypes of category combinations conflict, they shift to a more generative thinking (demonstrated by an increased use of emergent attributes). In short, when perceiving counter-stereotypes, in order to resolve the inconsistency perceivers shift out of a default heuristic thinking to a more systematic, and analytic cognitive style.

\section{Generalized Benefits of Counter-stereotypic Thinking}

Drawing on the aforementioned findings, in their Categorization-Processing-AdaptationGeneralization (CPAG) model Crisp and Turner (2011) argued that the process of inconsistency resolution outlined above entails two processes: the inhibition of existing stereotypes, and a creative reconstrual of the target at hand. These two processes are said to lessen reliance on memory structures such as stereotypes, and facilitate impressions based on individuating and emergent attributes (resulting in enhanced cognitive flexibility). Inhibiting heuristic thought implies a tendency to ignore immediately obvious or dominant solutions to problems, thus freeing up resources for generative thinking. Cognitive flexibility, broadly construed, includes actively choosing cognitive strategies that fit individuals' goals at that time (Showers \& Cantor, 1985), intelligently adapting to one's environment (Berg \& Sternberg, 1985), and creative thinking finding unusual yet relevant solutions (e.g., Isen, Daubman, \& Nowicki, 1987). Recent work by 
Gocłowska, Crisp, and Labuschagne (2012) provided initial evidence that gender counterstereotypes can be particularly effective in instigating different facets of cognitive flexibility. They showed that being encouraged to think about a gender counter-stereotypic vs. stereotypic target leads to the generation of a higher number of ideas, as well as more flexible and more original ideas on a divergent creativity task. In the present work, we test the impact of gender counter-stereotypes on cognitive flexibility in terms of avoiding heuristic thought and in turn engaging in systematic processing. Crucially, Crisp and Turner's (2011) CPAG model proposed that processing characteristics, once initiated by new and unexpected information, can become chronically or temporarily accessible in the form of a cognitive style or mindset. If this is the case, this means that counter-stereotypic interventions may have much broader impact than previously thought, such that this temporary cognitive shift of thinking which is less reliant on stored (stereotypic) knowledge may improve judgments towards a range of other groups who may typically be unfairly stereotyped.

Mindsets are content-free processing orientations that are often linked to goals (Armor \& Taylor, 2003; Gagne \& Lydon, 2001; Taylor \& Gollwitzer, 1995), thus impact judgments independently of the context in which they were elicited. Very few studies have investigated the impact mindsets can have on group-based impressions, and they have been explored in very different contexts to the one we are testing, focusing on different cognitive mechanisms. For instance, in the context of the Israeli-Palestinian conflict, Halperin, Russell, Trzesniewski, Gross, and Dweck (2011) aimed to change people's beliefs about outgroup malleability by inducing different ways of thinking. Across four experiments, Halperin and colleagues showed that inducing individuals with beliefs about the malleable versus fixed nature of groups encouraged more positive attitudes towards the outgroup, which then led to greater willingness to compromise for peace. That the intervention did not mention specific adversary groups during the induction stage, speaks to the viability of developing interventions that tackle people's core cognition (i.e., the mindset they adopt when thinking about outgroups) rather than the content of their specific prejudices. Similarly, the recent work of Tadmor, Chao, Ying-yi Hong, and Polzer (2013) shows the reversed relationship 
between cognitive capacity and group-based impressions. These authors demonstrated for the first time that racial essentialism, which is strongly related to stereotyping, can hamper creativity and this relationship is explained by closed-mindedness. The fact that racial essentialism appears to exert its negative effects on creativity attests that it is the style of information processing rather than the content of one's thinking that affects subsequent unrelated cognitive and social processes (Leung \& Chiu, 2010; Tadmor et al., 2013; Tadmor, Tetlock, \& Peng, 2009). More recently, Vasiljevic and Crisp (2013) showed that when participants were put in a counter-stereotypic mindset by generating five counter-stereotypic category combinations, they subsequently exhibited lowered prejudice and increased generalized tolerance and egalitarianism towards multiple stigmatized outgroups (elderly, disabled, asylum seekers, HIV patients, and gay men). Interestingly, this intervention also enhanced generalized trust towards a multitude of outgroups in a context of historic violent intergroup conflict on the territory of the Former Yugoslavia. In this intervention, participants were free to generate their own category combinations and these combinations varied widely between participants. Examples of category combinations generated by people carrying out the counter-stereotypicality task included: overweight - model, rich - student, female - firefighter, male - midwife, female - mechanic, black - president, blind-painter, and so on. Conversely, people carrying out the stereotypicality task generated combinations including: skinny - model, poor student, male - firefighter, female - midwife, male - mechanic, white - president, sighted-painter, and many others. The fact that the novel intervention did not include a specific outgroup target may explain why it had more success than previous interventions at promoting generalized tolerance. The counter-stereotypic category combinations generated differed widely between participants, and more importantly these combinations differed from the multiple target outgroups that were used as a measure of generalized prejudice reduction.

Based on the above, our contention is that forming an impression of a target with counterstereotypic information may not only have an impact on the target at hand, but can stimulate a nonheuristic, systematic processing style which, in turn, may impact subsequent judgements on 
unrelated objects of cognition (see Crisp \& Turner, 2011). In particular, in the light of research showing the relevance of gender categorization in social perception (Stangor, Lynch, Duan, \& Glass, 1992), we propose that thinking about a gender counter-stereotype may shift individuals out of heuristic modes of thinking, and in turn, remove the categorization prerequisite for intergroup bias. Because we propose a shift in mindset, the implication is that challenging gender stereotypes may promote lesser intergroup bias in general (i.e., towards a range of different groups). To provide the strongest possible test of this hypothesis, we sought to include measures of the most heinous and persistent forms of intergroup bias, dehumanization.

\section{Dehumanization}

In recent years, an increasing corpus of studies has shown the relevance and persistence of dehumanization, the tendency to consider others as less human than ourselves (Haslam, 2006). People, for instance, attribute human characteristics (e.g., curiosity, selfishness) to greater extent to themselves and their ingroup rather than to members of outgroups. Perceiving particular groups or individuals as subhuman can form the basis for justifying social and moral exclusion (Opotow, 1990). Numerous scholars have connected dehumanization of victims to mass atrocities, such as genocide and ethnic cleansing (Bar-Tal, 1990; Kelman, 1973; Opotow, 1990; Staub, 1989). Thus, the denial of others' humanness can serve to justify the most atrocious forms of aggression and discrimination towards them (Bain, Park, Kwok, \& Haslam, 2009; Castano \& Giner-Sorolla, 2006; Cuddy, Rock, \& Norton, 2007; Haslam, Loughnan, Kashima, \& Bain, 2008).

For the purposes of our paper we examine two theoretical strands of the dehumanization literature, namely theorizing on infrahumanization (Leyens et al., 2000; Leyens et al., 2001), and theorizing on the distinction between animalistic and mechanistic dehumanization (Haslam, 2006). Leyens and colleagues were the first to relate dehumanization to ingroup bias, by showing that people attribute more secondary or uniquely human emotions to their ingroup than they do to relevant outgroups. Recently, Haslam (2006) extended these findings and distinguished between animalistic dehumanization, the denial of uniquely human traits (i.e., civility, refinement) from 
mechanistic dehumanization, which implies the denial of human nature traits (i.e., interpersonal warmth, openness). Even though dehumanization constitutes arguably one of the most fundamental sources of intergroup bias, to date, very little is known of the socio-cognitive processes that can inhibit this phenomenon. An exception is the work by Costello and Hodson (2010) showing that heightened beliefs in animal-human similarity (by activating the super-ordinate common group of animals) can enhance the attribution of human traits to immigrants. Moreover, positive contact with outgroup members has been shown to reduce dehumanization (Brown, Eller, Leeds, \& Stace, 2007; Tam et al., 2007), and leads to reduced anxiety and higher empathy, which are proximal predictors of outgroup humanization (Capozza, Trifiletti, Vezzali, \& Favara, 2013). Albarello and Rubini (2012) have also recently demonstrated that dehumanization towards Black people can be reduced by reminding participants of their human identity and the cross-cutting multiple categories that they share with their targets of prejudice. In short, this research suggests that a pre-requisite for dehumanization is the categorization in to 'us' and 'them'. As such, promoting such a mindset in which people no longer rely on heuristics (i.e., categorization) should correspondingly remove the cognitive pre-requisite for dehumanization.

\section{The Present Research}

In this research we focused on gender counter-stereotypes as a way of challenging social stereotypes. This is because past research has shown gender is a categorization that is almost universally applied in impression formation (Stangor, et al., 1992). On the basis of predictions derived from Crisp and Turner's (2011) CPAG model and the research reviewed above we hypothesize that 1) Counter-stereotypic thinking will promote generalized tolerance manifested as a reduced tendency to dehumanize a range of outgroups unrelated to gender (generalized humanization hypothesis); 2) Counter-stereotypic thinking will promote a reduced reliance on heuristic thinking (heuristic thinking hypothesis); 3) Reduced heuristic thinking triggered by counter-stereotypes will mediate generalized humanization (mediational hypothesis). 
To test these hypotheses we conducted a pilot study and two experiments. In all studies we used a counter-stereotypicality task that has been widely used in past literature (Hutter \& Crisp, 2005, 2006; Kunda et al., 1990). Specifically, we asked participants to consider a gender counterstereotypic combination (female mechanic; compared to controls) and list all words that come to mind in a limited amount of time. In the pilot study we established the efficacy of this manipulation for the purposes of the current investigation. In Experiment 1 we tested the generalized humanization hypothesis. In Experiment 2 we aimed to replicate the findings of Experiment 1 with an alternative measure of dehumanization as well as to test the heuristic thinking and mediation hypotheses.

\section{Pilot Study}

A great deal of previous research has shown that stereotypic thinking is the default mode of social perception (Brewer, 1988; Fiske \& Neuberg, 1990; McConnell, Hamilton, \& Sherman, 1994; Hastie et al., 1990; Kunda et al., 1990; Sherman \& Frost, 2000). Nonetheless, in an initial Pilot Study we sought to confirm this for the current project and materials. We hypothesized that participants asked to think of gender counter-stereotypic targets (female mechanic, male midwife) will find these targets more surprising, less familiar, and will individuate them more when opposed to participants asked to think of stereotypic combinations (female midwife, male mechanic), and also compared to participants who were asked to think of basic gender categories (female, male). Furthermore, in line with previous literature showing that stereotypic thinking is the default mode of thinking, we hypothesised that there will be no significant difference in surprise, familiarity and individuation between those participants who thought of stereotypic combinations and those who thought of basic gender categories.

\section{Method}

\section{Participants and Design}

Ninety-one students (57 females and 34 males, $\left.M_{\text {age }}=21.70, S D=3.41\right)$ were randomly assigned to one of three conditions, whereby they were asked to think about and write down up to a 
maximum of 20 characteristics: either on a gender counter-stereotypic target (female mechanic, or male midwife); a gender stereotypic target (male mechanic, or female midwife); or baseline gender targets alone (female, or male).

\section{Procedure and Materials}

After the manipulation, we asked participants to self-report how surprising and familiar they found the categories that they were asked to think of. Answers were recorded on Likert-type scales anchored from 1 (Not at all) to 7 (Very much). These particular items were chosen in line with previous studies that have utilised similar scales to measure the surprise and familiarity associated with different social category conjunctions that were presented to participants (Kunda et al., 1990). Drawing from Hutter and colleagues' (2013) study we measured participants' individuation of the targets they were presented with. Participants were asked to indicate "how much do you view the target described above as ..." $(1=$ individual, $7=$ group member $)[\mathrm{R}]$; "to what extent do you think of the target described above as unique individual" $(1=$ not at all, $7=$ very much $)$; "to what extent does the type of person qualify as a typical group member" $(1=$ not at all, $7=$ very much $)[\mathrm{R}]$; "how similar are individual members of the above group to other members of the same group?" $(1=$ not at all similar, $7=$ very similar $)[\mathrm{R}]$. Items denoted with $\mathrm{R}$ were reversed-scored, such that higher scores represent higher individuation. An index of target individuation was created (Cronbach's $\alpha=.82$ ).

\section{Results and Discussion}

We conducted a sequence of 3 (combination type: counter-stereotypic vs. stereotypic $v s$. baseline) x 2 (target gender: male $v s$. female) x 2 (participants gender: male $v s$. female) between subjects ANOVAs on surprise, familiarity and target individuation. As expected, counterstereotypic combinations were perceived as more surprising $(M=5.97 ; S D=1.06)$, when compared to stereotypic combinations $(M=2.07 ; S D=0.78, p<.001)$, and when compared to baseline $(M=$ 2.06; $S D=0.89, p<.001) ; F(2,91)=165.81, p<.001, \eta^{2}=.801$. There was no significant difference between stereotypic and baseline conditions, $p=.865$. No other effect was significant 
(target gender: $F(1,91)=4.42, p=.05, \eta^{2}=.053$; and participants' gender: $F(1,91)=0.00, p=$ $\left..987, \eta^{2}=.000\right)$. Furthermore, counter-stereotypic combinations $(M=3.30 ; S D=1.34)$ were perceived as less familiar than stereotypic combinations $(M=5.94 ; S D=0.64, p<.001)$, and baseline $(M=5.88 ; S D=0.74, p<.001) ; F(2,91)=71.90, p<.001, \eta^{2}=.646$. There was no significant difference between stereotypic and baseline conditions, $p=.973$. No other effect was significant (gender target: $F(1,91)=1.85, p=.176, \eta^{2}=.023$; and participants' gender: $F(1,91)=$ $\left.0.50, p=.486, \eta^{2}=.006\right)$.

In terms of individuation, counter-stereotypic combinations $(M=4.78 ; S D=0.98)$ led to increased target individuation when compared to stereotypic combinations $(M=2.94 ; S D=0.52, p$ $<.001)$, and when compared to baseline $(M=3.31 ; S D=0.87, p<.001) ; F(2,91)=34.61, p<.001$, $\eta^{2}=.464$. There was no significant difference between stereotypic combinations and baseline conditions, $p=.112$. No other effect was significant (target gender: $F(1,91)=0.14, p=.701$; and participants' gender: $F(1,91)=0.03, p=.851)$.

These results coupled with prior literature on stereotyping confirm that stereotypic combinations can be successfully used as a proxy for the baseline default thinking mode. Since we aimed to give participants tasks of equivalent load in Experiment 1 and 2 we decided to ask participants to think of stereotypic combinations as our control condition.

\section{Experiment 1}

Experiment 1 tested the generalized humanization hypothesis on attitudes toward stigmatized minority groups. Participants provided judgments on four outgroup targets: asylum seekers, physically disabled people, elderly, and homeless people. The outgroups were chosen to be stigmatized on one or both dimensions as defined by the Stereotype Content Model (SCM; Fiske, Cuddy, Glick, \& Xu, 2002). Fiske and colleagues demonstrated that groups are evaluated along two primary characteristics: warmth and competence. For instance, physically disabled, elderly and learning disabled people are usually perceived as warm but incompetent. The homeless and asylum 
seekers are perceived as neither warm nor competent, thereby eliciting disgust and avoidance (Cuddy \& Fiske, 2002; Cuddy, Fiske, \& Glick, 2007; Fiske et al., 2002; Glick \& Fiske, 2001). Furthermore, according to Haslam (2006) targets such as physically disabled and people with schizophrenia are essentialized groups, in the sense that the denial of their human essence is attributed to inborn aspects instead of socially shaped, as it is the case for asylum seekers and the homeless. We therefore chose a selection of outgroups all of whom past research has shown to be viewed negatively on one or both of these dimensions, and who have a tendency to be dehumanized.

If gender counter-stereotypes trigger a cognitive style characterized by a lesser reliance on heuristic thinking, then this should be reflected in evaluations of diverse groups unrelated to gender (because existing stereotypes of those groups should no longer influence attitudes towards them). In particular, drawing from Haslam (2006) we asked participants to attribute human traits to outgroup members. A large amount of recent research has shown the persistence and pervasiveness of the tendency to deny outgroup members human characteristics; that is, dehumanization. We tested whether being compelled to think about gender counter-stereotypic targets leads to increased generalized "humanization" of multiple outgroups through the attribution of human traits.

\section{Method}

\section{Participants and Design}

Eighty students (46 females and 34 males, $M_{\text {age }}=19.6, S D=2.42$ ) were randomly assigned to a counter-stereotypic or stereotypic condition.

\section{Procedure and Materials}

Participants were asked to think about either a counter-stereotypic category combination (female mechanic, or male midwife), or a stereotypic category combination (male mechanic, or female midwife), then they were given two minutes to generate as many adjectives as possible of the presented combination (Hutter \& Crisp, 2005) before receiving the dependent measures.

\section{Dependent variables}


Human traits attributions. According to Haslam (2006) we can differentiate two senses of humanness which are both essential to describe human beings. Human uniqueness (HU) characteristics define the boundary that separates human beings from animals, involving refinement, civility, morality, and higher cognition. Human nature $(\mathrm{HN})$ characteristics distinguish humans from inanimate things, concerning emotional responsiveness, cognitive openness, agency, and individuality. The extent to which these uniquely human and human nature traits are denied to outgroup members constitutes a measure of the broader concept of dehumanization (see also Leyens et al., 2000; 2001).

Participants were asked to define whether an average member of four minority social groups (asylum seekers, physically disabled people, elderly, and homeless people) possessed a series of characteristics compared to the average population on a 7 -point scale $(1=$ much less than average population to $7=$ much more than average population). Specifically, participants rated the extent to which each social group possesses a series of twenty human traits compared to the average population. Ten traits referred to human uniqueness (i.e., idealism, carefulness) and ten referred to human nature (i.e., curiosity, selfishness).

Perceived counter-stereotypicality. Participants were also required to indicate to what extent they perceived the target as surprising, familiar (R), easy to process $(\mathrm{R})$ on a scale from 1 (Not at all) to 5 (Very much) as manipulation check (Hutter \& Crisp, 2005). We then created an index of perceived counter-stereotypicality $(\alpha=.77)$.

\section{Results and Discussion}

\section{Perceived Counter-stereotypicality}

A 2 (combination type: counter-stereotypic $v s$. stereotypic) x 2 (target gender: male $v s$. female) between subjects ANOVA yielded a main effect of combination type. Counter-stereotypic category combinations were perceived as more counter-stereotypic $(M=3.17, S D=0.76)$ than stereotypic combinations $(M=2.02, S D=0.74), F(1,80)=45.25, p=.003, \eta^{2}=.369$. As expected, 
there was no significant effect of target gender, $F(1,80)=0.45, p=.501, \eta^{2}=.000$, nor a significant interaction, $F(1,80)=0.83, p=.365, \eta^{2}=.011$.

\section{Human Trait Attributions}

Following established practice in the literature, we created two single indices of Human Nature and Human Uniqueness ascribed for each of the four different outgroups after reverse scoring the negatively worded items ${ }^{1}$ (Haslam, 2006; Haslam et al., 2005). As shown in Table 1, human nature and human uniqueness trait attributions to each ougroup were positively correlated.

Human nature. A 2 (combination type: counter-stereotypic vs. stereotypic) x 2 (target gender: male $v s$. female) MANOVA was computed on the ratings of human nature for the four outgroups. The analysis revealed that participants in counter-stereotypic category combinations (irrespective of the gender composition of that combination) assigned greater human nature to the four outgroups $(M=4.30 ; S D=0.71)$, when compared to the participants in stereotypic combinations $(M=3.68 ; S D=0.74), F(1,76)=8.90, p=.004, \eta^{2}=.105$. No other effects were significant, $F s<1.75$. Confirming that the impact of the counter-stereotyping task affected all targets equally, further analysis revealed that the effects of combination type did not differ between the four outgroups, $F(2.64,200)=0.62, p=.583, \eta^{2}=.008$ (after correcting for violations of sphericity).

Human uniqueness. A 2 (combination type: counter-stereotypic vs. stereotypic) x 2 (target gender: male $v s$. female) MANOVA on the ratings of human uniqueness revealed that participants who made an impression of a counter-stereotypic target (irrespective of the gender composition of that combination) assigned more human uniqueness to all four different outgroups $(M=4.32 ; S D=$ $0.82)$, when compared to participants who made an impression of a stereotypic target $(M=3.47 ; S D$ $=0.82), F(1,76)=29.23, p<.001, \eta^{2}=.278$. No other effects were significant, $F s<1.23$. As above, further analysis that tests for differences in dehumanization reduction between all outgroups, revealed that the interaction between combination type and outgroups was not significant, $F(2.83$, $215)=0.32, p=.796, \eta^{2}=.004$ (after correcting for violations of sphericity), thus confirming our 
generalized humanization hypothesis. Table 2 shows individual means and standard deviations of the human nature and human uniqueness traits attribution to each of the four outgroups.

In sum Experiment 1 confirmed the humanizing effects of perceiving gender counterstereotypic category combinations. Even though participants formed an impression of a person (female midwife/mechanic) entirely unrelated to the target outgroups (asylum seekers, physically disabled people, elderly, and homeless people), the counter-stereotypic combination led to lower bias against all of these target groups. This is consistent with our heuristic-switching hypothesis: Forming an impression of a counter-stereotypic target led to lesser reliance on stereotypic thinking, evident in higher ascription of human nature and human uniqueness, meaning inclusion in the human group.

\section{Experiment 2}

The aim of Experiment 2 was to collect converging evidence of the generalized humanization effects revealed by Experiment 1 with a complementary measure and to ascertain direct evidence of the role of systematic processing as the underlying mechanism mediating the generalization of humanness to a range of outgroups. More specifically, we tested whether gender counter-stereotypic targets promote a reduced reliance on heuristics. In other words, if thinking about gender counter-stereotypes stimulates finer-grained judgments based on non-heuristic thinking (Hutter \& Crisp, 2005), this would explain decreased dehumanization observed across multiple stigmatized outgroups (asylum seekers, homeless people, learning disabled people and people with schizophrenia). To further extend the findings of our first experiment, we employed a complementary measure of humanization based on a specific form of dehumanization, infrahumanization (Leyens et al., 2000; 2001). According to Leyens and colleagues primary emotions (e.g., anger, excitement) are shared between humans and animals, whilst secondary emotions (e.g., admiration, regret) are only uniquely human states. Hence, infrahumanization refers to the belief that outgroup members are able to express primary but not secondary emotions to the same extent as ingroup members, which is reflective of the belief that they are less human than the 
ingroup (cf., Demoulin et al., 2004; Leyens et al., 2001). Leyens, Demoulin, Vaes, Gaunt, and Paladino (2007) argue that infrahumanization differs from dehumanization, since infrahumanization derives from an ingroup-outgroup comparison where the outgroup is simply regarded as less human, or more animal-like, than the ingroup. In contrast, dehumanization indicates an absolute judgment according to which outgroup members are not considered as humans. As such, for an inclusive test of the generalized impact of counter-stereotypes on dehumanizing forms of prejudice, we here employed a measure of infrahumanization.

\section{Method}

\section{Participants and Design}

A total of eighty students ( 62 females and 18 males; $M_{a g e}=19.4, S D=2.28$ ) were randomly assigned to a counter-stereotypic or stereotypic condition.

\section{Procedure and Materials}

The experimental manipulation was similar to the one used in the first experiment. Since the previous experiment showed no difference as a function of the gender of the counter-stereotypic (stereotypic) category combinations, in Experiment 2 we considered only female category combinations whose stereotypes are perceived as more wide-spread, and resistant across time and cultures (Eagly \& Mladinic, 1989; Eagly \& Steffen, 1984). Participants were asked to form an impression of either a counter-stereotypic category combination (female mechanic) or a stereotypic category combination (male mechanic). In line with previous research on impression formation participants were given two minutes to generate as many adjectives as possible of the presented combination (Hutter \& Crisp, 2005) before receiving the dependent measures.

\section{Dependent variables}

Heuristic thinking. Drawing upon measures used by Tversky and Kahneman (1974) participants were then given ten reasoning problems. They were instructed to solve as many of the problems as they could within a timeframe of ten minutes. An example of the reasoning problems follows: "A bat and a ball cost $£ 1.10$ in total. The bat costs $£ 1$ more than the ball. How much does 
the ball cost?" The correct answer is 5 cents, but usually people tend to say 10 cents. Answers on the reasoning problems were coded dichotomously with 1 denoting a correct answer and 0 a wrong answer. Ratings on the ten reasoning problems had good internal reliability with a Cronbach's $\alpha$ of .73 , thus were collapsed in a single index.

Primary and secondary emotions. Participants were then asked to define how much they think the average member of four stigmatized social groups (asylum seekers, learning disabled people, people with schizophrenia, and homeless people) experiences twelve emotions compared to the average population on a 7 -point scale $(1=$ infrequently experiences to $7=$ frequently experiences). Emotional terms were chosen from Paladino and Vaes' (2000) pre-test conducted on the Italian translations of emotions. Primary emotions measured ascriptions of pleasure, happiness, desire, fear, pain, and rage. Secondary emotions measured ascriptions of embarrassment, remorse, melancholy, shame, compassion, and pride. Words denoting negative and positive emotions were equally balanced across the measures of primary and secondary emotions (Demoulin et al., 2004). The order of the emotions was randomized.

Perceived counter-stereotypicality. As in Experiment 1, participants indicated to what extent they perceived the target as surprising, familiar (R), easy to process (R) on a scale from 1 (Not at all) to 5 (Very much). We then created an index of perceived counter-stereotypicality $(\alpha=$ $.69)$.

\section{Results and Discussion}

\section{Perceived Counter-stereotypicality}

A 2 (combination type: counter-stereotypic vs. stereotypic) between subjects ANOVA yielded a main effect of combination type. Counter-stereotypic category combinations were perceived as more counter-stereotypic $(M=3.59, S D=0.65)$ than stereotypic categorizations $(M=$ 2.07, $S D=0.88), F(1,76)=75.46, p=.002, \eta^{2}=.492$.

\section{Heuristic Thinking}


An independent samples $t$-test showed that participants who formed an impression of a counter-stereotypic target relied less on heuristic thinking and got a higher number of correct answers when solving Tversky and Kahneman's (1974) conundrums $(M=5.13, S D=1.98)$, compared to participants who formed an impression of a stereotypic target $(M=3.5, S D=1.85)$, $t(78)=-3.79, p<.001, r=.39$. This indicated participants had switched out of a heuristic way of thinking, and utilised a more systematic approach to problem solving, supporting the heuristic thinking hypothesis.

\section{Primary and Secondary Emotions}

Single indices of primary and secondary emotions for each of the four different outgroups were created ${ }^{2}$. A MANOVA was computed on the ratings of primary emotions for the four outgroups, revealing as expected that there was no significant difference in the ratings of primary emotions assigned to the four outgroups as a function of the counter-stereotypicality of the impression formation target, $F(4,75)=1.81, p=.135, \eta^{2}=.088\left(M_{\text {counter-stereotypic }}=4.24, S D=0.42\right.$ vs. $\left.M_{\text {stereotypic }}=4.39, S D=0.43\right)$.

In contrast, the MANOVA on the ratings of secondary emotions revealed that participants who formed an impression of a counter-stereotypic target attributed more secondary emotions to all four different outgroups $(M=4.85, S D=0.71)$, when compared to participants who made an impression of a stereotypic target $(M=3.89, S D=0.53), F(4,75)=3.65, p=.01, \eta^{2}=.161$. For individual means and standard deviations of the primary and secondary emotions attributed to each of the four outgroups see Table 3. Further analysis with combination type as a between-subjects factor showed that the effect of combination type did not differ between the four outgroups, $F(3$, 234) $=2.58, p=.066, \eta^{2}=.031$ supporting the generalized humanization hypothesis.

\section{Mediational Analysis}

We computed a mediational analysis to test reduced reliance on heuristic thinking as a mediator in the relationship between combination type and generalized attribution of secondary emotions towards the four outgroups $(\alpha=.67)$, using Preacher and Hayes' (2008) bootstrapping 
procedure. As expected, we found a significant path between combination type and aggregated secondary emotions $(\beta=.34, p<.005)$. Combination type also predicted the mediator, reduced heuristic thinking or systematic processing $(\beta=.39, p<.005)$. The path between systematic processing and secondary emotions was also significant $(\beta=.40, p<.005)$. However, when the mediator was controlled $(\beta=.32, p<.05)$ the relationship between combination type and secondary emotions became non-significant $(\beta=.22, p=.555)$. The lack of the presence of a zero within the $95 \%$ confidence intervals $(\mathrm{LLCI}=.0359, \mathrm{ULCI}=.3550)$ demonstrated that reduced general tendency to engage in heuristic thinking elicited by counter-stereotypic combinations mediated the effect on attribution of secondary emotions to outgroups.

Experiment 2 supported the hypothesis that perceiving counter-stereotypic category combinations reduces reliance on heuristics, which, in turn, helps explain tendencies towards generalized humanization. Participants who thought of a counter-stereotypic category combination relied less on heuristics in problem solving than people who thought of a stereotypic category combination. Previous research has shown that the perception of others along multiple counterstereotypic categories decreases intergroup prejudice towards the target considered (Crisp, Hewstone, \& Rubin, 2001), as well as increasing generalized tolerance (Vasiljevic \& Crisp, 2013). This experiment demonstrates that the effects of thinking about a counter-stereotypic combination can also reduce dehumanizing prejudice towards multiple outgroups via reductions in heuristic thinking. After thinking about a counter-stereotypic category combination, participants were more likely to attribute secondary and not primary emotions towards different stigmatized outgroups.

\section{General Discussion}

Our research tested the viability of counter-stereotypic thinking as a means of reducing generalized tendencies to dehumanize outgroups, via a reduced reliance on heuristic thinking. In Experiment 1 we employed Haslam's (2006) concepts of human nature and human uniqueness and demonstrated that forming an impression of gender counter-stereotypic category combination led to an enhanced attribution of human traits to four different outgroups, Experiment 2 confirmed these 
findings on measures of infrahumanization. Specifically, our results showed that thinking of female counter-stereotypes increased the attribution of secondary emotions toward multiple stigmatized outgroups. Importantly, we also found support for the hypothesized mediating role of reduced heuristic processing arising from counter-stereotypic thinking.

These findings go beyond previous evidence supporting the assumption that not just increasing the number of categorical dimensions (Albarello \& Rubini, 2012), but increasing the complexity of their interrelations, can lead to reductions in dehumanization. Even more interestingly, this effect was extended to multiple unrelated and stigmatized outgroups. We were able to show that generating counter-stereotypes led to a generalized humanization process towards a variety of outgroups usually targeted via diverse forms of discrimination. The range of outgroups included stereotypically distinct targets (see Fiske et al., 2002). In this vein, exposing people to counter-stereotypic information can be conceived as a promising intervention to counteract prejudice against deeply stigmatized social groups. This compelling result also extends the role of gender counter-stereotypes in promoting cognitive flexibility. Another novel aspect of these findings concerns the evidence that cognitive flexibility not only improves judgment accuracy, but also promotes an enlargement of human group boundaries. In other words, we showed that gender counter-stereotypes have an important role to play in improving intergroup relations.

The relevance of these findings lies in the pervasiveness of dehumanizing prejudice (Haslam, 2006), as well as in the potential implications of increasing perceptions of stigmatized groups as fully human. Indeed it emphasizes outgroup members' belonging to the moral human community, and this as literature shows (Opotow, 1990), prevents them from being subjected to the most extreme forms of discrimination, assuring common rights and reciprocal respect.

\section{Limitations and future directions}

First, the use of a specific gender-occupation counter-stereotype did not allow generalization of the interventions' validity to other types of category conjunction. Future research should address this limitation by considering alternative (or additional) counter-stereotypic exemplars. In this 
regard, it is possible that counter-stereotypic thinking can benefit from only chronically accessible categories like gender, such as race, age, and physical appearance (cf. Bargh \& Thein, 1985; Higgins \& King, 1981). However, prior research has also shown that, except for highly racially prejudiced perceivers, people make greater use of gender than race as a category because they find gender differences more informative than race differences (Stangor et al., 1992). This highlights the strength of surprising gender-based category combinations to reduce wider prejudice, suggesting that counter-stereotypes of other highly relevant groups may not produce the same strength of effect, or their efficiency may be limited on the basis of the importance attributed by perceivers to the categories considered.

However, it is noteworthy that research by Vasiljevic and Crisp (2013), who asked participants to generate their own unique counter-stereotypic category combinations, demonstrated increases in generalized tolerance towards multiple outgroups. Indeed, in this spontaneous generation task it is likely that participants combined social categories that they perceived as most relevant and informative. Hence, if our manipulation was extended to test other counter-stereotypic conjunctions similar decreases in generalized dehumanization might be achieved only when perceivers regarded the categories considered as relevant to the task at hand.

Second, research on expectancy violation has shown several important short-term effects including enhanced attention and more elaborate processing (see Roese \& Sherman, 2007). This would suggest the humanizing effects of counter-stereotypes may be short-lived. Future research should address this issue in more detail. However, we would argue that, as proposed by Crisp and Turner's (2011) CPAG model, repeated exposure to counter-stereotypic diversity should lead to an adaptive tendency to think more flexibly, in general, and in a range of domains.

Another important thing to note is that counter-stereotypic thinking can backfire. McKimmie, Master, Masser, Schuller, and Terry (2013) showed that the benefit of the more accurate impression formation elicited by counter-stereotypes comes at a cost. Specifically, they found that processing counter-stereotypes led to reduced attention for contextual features that 
eventually altered decision making about a target involved in a criminal case investigation. Future empirical investigations should further examine any such paradoxical effects of counter-stereotypic thinking.

Finally, counter-stereotypic exemplars are sometimes subtyped, which leaves the initial stereotype intact (Weber \& Crocker, 1983). Subtyping is particularly pronounced for extreme exemplars (Kunda \& Oleson, 1997), raising doubts about the usefulness of counter-stereotypic thinking about extreme exemplars. However, research has also demonstrated that subtyping ensues in the presence of further, often neutral information (e.g., an introverted lawyer working in a small or big firm), but it tends not to occur when only category information is available (e.g., an introverted lawyer) [Kunda \& Oleson, 1995]. We surmise that subtyping did not occur in our experiments because we did not provide participants with any additional information apart from the given category combination.

\section{Conclusions}

These findings suggest that efforts to promote social and cultural diversity - specifically those that focus on counter-stereotypes - may be of value not just because they reduce discrimination of the target at hand, but because they can foster a lesser reliance on heuristic thinking, and lead to greater humanization of a range of different stigmatized groups. In other words, counter-stereotypes can have generalized effects on the perception of groups, and importantly, they extend social inclusion of outgroup members to the overarching category of humankind.

The mechanism underlying this effect - a switching from heuristic to systematic thinking has potentially profound implications for attempts to foster diversity. It demonstrates that counterstereotypes may be of value not only because they can foster equality, but because they can improve individuals' capacity for cognitive flexibility, helping them avoid the typical biases that hamper judgment and decision-making in everyday life. Importantly, this may provide the intrinsic motivation for engaging in social and cultural diversity programs that has been missing in the past. 
Majority groups typically prefer assimilation-like strategies of social integration, likely because true equality means, for them, giving up resource. However, if it is substantiated that engaging in social diversity programs promotes individually enhanced cognitive capacity, this may provide a significant incentive to engage in such programs in the future.

\section{References}

Albarello, F., \& Rubini, M. (2012). Reducing dehumanization outcomes towards Blacks: The role of multiple categorization and of human identity. European Journal of Social Psychology, 42, 801-938. doi: 10.1482/26760

Armor, D., \& Taylor, S. (2003). The effects of mindset on behaviour: self-regulation in deliberative and implementational frames of mind. Personality and Social Psychology Bulletin, 29, 8695.doi: $10.1177 / 0146167202238374$

Bain, P., Park, J., Kwok, C., \& Haslam, N. (2009). Attributing human uniqueness and human nature to cultural groups: Distinct forms of subtle dehumanization. Group Processes \& Intergroup Relations, 12, 789-805. doi: 10.1177/1368430209340415

Bargh, J. A., \& Thein, R. D. (1985). Individual construct accessibility, person memory, and the recall-judgment link: The case of information overload. Journal of personality and Social Psychology, 49, 1129-1146. doi: 10.1037/0022-3514.49.5.1129.

Bar-Tal, D. (1990). Causes and consequences of delegitimization: Models of conflict and ethnocentrism. Journal of Social Issues, 46, 65-81.

Beaman, L., Chattopadhyay, R., Duflo, E., Pande, R., \& Topalova, P. (2009). Powerful Women: Does Exposure Reduce Prejudice?. Quarterly Journal of Economics, 124, 1497-1540.

Berg, C. A., \& Sternberg, R. J. (1985). Response to novelty: Continuity versus discontinuity in the developmental course of intelligence. Advances in child development and behavior, 19, 147. 
Blair, I. V., Ma, J. E., \& Lenton, A. P. (2001). Imagining stereotypes away: the moderation of implicit stereotypes through mental imagery. Journal of personality and social psychology, 81(5), 828. doi: 10.1037/0022-3514.81.5.828

Brewer, M. B. (1988). A dual process model of impression formation. In T. K. Srull \& R. S. Wyer Jr. (Eds.) Advances in Social Cognition (Vol. 1, pp. 1-36), Hillsdale, NJ: Erlbaum.

Brown, R., Eller, A., Leeds, S., \& Stace, K. (2007). Intergroup contact and intergroup attitudes: A longitudinal study. European Journal of Social Psychology, 37, 692-703. doi: 10.1002/ejsp.384

Capozza, D., Trifiletti, E., Vezzali, L., \& Favara, I. (2013). Can intergroup contact improve humanity attributions?. International Journal of Psychology, 48, 527-541.

Castano, E., \& Giner-Sorolla, R. (2006). Not quite human: Infra-humanization as a response to collective responsibility for intergroup killing. Journal of Personality and Social Psychology, 90, 804-818. doi: 10.1037/0022-3514.90.5.804

Costello, K., \& Hodson G. (2010). Exploring the roots of dehumanization: The role of animalhuman similarity in promoting immigrant humanization. Group Processes \& Intergroup Relations, 13, 3-22. doi: 10.1177/1368430210367867

Crisp R. J., \& Turner, R. (2011). Cognitive adaptation to the experience of social and cultural diversity. Psychological Bulletin, 137, 242-266. doi: 10.1037/a0021840

Cuddy, A. J. C., \& Fiske, S. T. (2002). Doddering, but dear: Process, content, and function in stereotyping of older persons. In T. D. Nelson (Ed.), Ageism (pp. 3-26). Cambridge, MA: MIT Press.

Cuddy, A. J. C., Fiske, S. T., \& Glick, P. (2007). The BIAS map: behaviors from intergroup affect and stereotypes. Journal of personality and social psychology, 92, 631-648. doi: $10.1037 / 0022-3514.92 .4 .631$ 
Cuddy, A. J. C., Rock, M., \& Norton, M. I. (2007). Aid in the aftermath of Hurricane Katrina: Inferences of secondary emotions and intergroup helping. Group Processes \& Intergroup Relations, 10, 107-118. doi: 10.1177/1368430207071344

Dasgupta, N., \& Asgari, S. (2004). Seeing is believing: Exposure to counterstereotypic women leaders and its effect on the malleability of automatic gender stereotyping. Journal of Experimental Social Psychology, 40(5), 642-658. doi:10.1016/j.jesp.2004.02.003

Demoulin, S., Leyens, J. P., Paladino, M. P., Rodriguez-Torres, R., Rodriguez-Perez, A., \& Dovidio, J. F. (2004). Dimensions of "uniquely" and "non-uniquely" human emotions. Cognition and Emotion, 18, 71-96. doi: 10.1080/0699930244000444

Eagly, A. H., \& Mladinic, A. (1989). Gender stereotypes and attitudes toward women and men. Personality and Social Psychology Bulletin, 15, 543-558.

Eagly, A., \& Steffen, V. J. (1984). Gender stereotypes stem from the distribution of women and men into social roles. Journal of Personality and Social Psychology, 46, 735-754.

Fiske, S. T., Cuddy, A. J. C., Glick, P., \& Xu, J., (2002). A model of (often mixed) stereotype content: Competence and warmth respectively follow from perceived status and competition. Journal of Personality and Social Psychology, 82, 878-902. doi: $10.1037 / / 0022-3514.82 .6 .878$

Fiske, S. T., \& Neuberg, S. L. (1990). A continuum model of impression formation, from categorybased to individuating processes: Influence of information and motivation on attention and interpretation. In M. P. Zanna (Ed.), Advances in experimental social psychology (pp. 1-74). New York: Academic Press.

Gagne, F. M., \& Lydon, J. E. (2001). Mind-set and close relationships: When bias leads to (in)accurate predictions. Journal of Personality and Social Psychology, 81, 85-96. doi: $10.1177 / 0146167201279007$

Glick, P., \& Fiske, S.T. (2001). An ambivalent alliance: Hostile and benevolent sexism as complementary justifications for gender inequality. American Psychologist, 56, 109-118. 
Gocłowska, M. A., Crisp, R. J., \& Labuschagne, K. (2013). Can counter-stereotypes boost flexible thinking?. Group Processes \& Intergroup Relations, 16, 217-231. doi: $10.1177 / 1368430212445076$

Halperin, E., Russell, G. A., Trzesniewski, H. K., Gross, J. J., \& Dweck, S.C. (2011) Promoting the peace process by changing beliefs about group malleability. Science, 333, 1767-1769.

Haslam, N. (2006). Dehumanization: An integrative review. Personality and Social Psychology Review, 10, 252-264.

Haslam, N., Bain, P., Douge, L., Lee, M., \& Bastian, B. (2005). More human than you: attributing humanness to self and others. Journal of personality and social psychology, 89(6), 937-950. doi: $10.1037 / 0022-3514.89 .6 .937$

Haslam, N., Loughnan, S., Kashima, Y., \& Bain, P. (2008). Attributing and denying humanness to others. In W. Stroebe e M. Hewstone (Eds.), European Review of Social Psychology (pp. 55-85). London: Psychology Press.

Hastie, R., Schroeder, C., \& Weber, R. (1990). Creating complex social conjunction categories from simple categories. Bulletin of the Psychonomic Society, 28, 242-247.

Higgins, E. T., \& King, G. (1981). Accessibility of social constructs: Information-processing consequences of individual and contextual variability. In N. Cantor \& J. E Kihlstrom (Eds.), Personality, cognition and social interaction (pp. 69-121). Hillsdale, N J: Erlbaum.

Hutter, R. R. C. \& Crisp R. J. (2005). The composition of category conjunctions. Personality and Social Psychology Bulletin, 31, 647-657. doi: 10.1177/0146167204271575

Hutter, R. R. C. \& Crisp, R. J. (2006). Implications of cognitive busyness for the perception of category conjunctions. Journal of Social Psychology, 146, 253-256. doi: 10.3200/SOCP.146.2. 253-256 
Hutter, R. R. C., Crisp R. J., Humphreys G. W., Waters G. M., \& Moffitt G. (2009). The dynamics of category conjunctions. Group Processes Intergroup Relations, 12, 673-686. doi: $10.1177 / 1368430209337471$

Isen, A. M., Daubman, K. A., \& Nowicki G. P. (1987). Positive affect facilitates creative problem solving. Journal of Personality and Social Psychology, 52, 1122-1131.

Jost, J. T., \& Kay, A. C. (2005). Exposure to benevolent sexism and complementary gender stereotypes. Journal of Personality and Social Psychology, 88, 498-509. doi: 10.1037/00223514.88.3.498

Kawakami, K., Dovidio, J. F., \& Van Kamp, S. (2005). Kicking the habit: Effects of nonstereotypic association training and correction processes on hiring decisions. Journal of Experimental Social Psychology, 41, 68-75. doi: 10.1016/j.jesp.2004.05.004

Kelman, H. C. (1973). Violence without moral restraint: Reflections on the dehumanization of victims and victimizers. Journal of Social Issues, 23, 25-61.

Kunda, Z., Miller, D. T., \& Claire, T. (1990). Combining social concepts: The role of causal reasoning. Cognitive Science, 14, 551-577.

Kunda, Z., \& Oleson, K. C. (1995). Maintaining stereotypes in the face of disconfirmation: constructing grounds for subtyping deviants. Journal of personality and social psychology, 68, 565-580. doi: 10.1037/0022-3514.68.4.565

Kunda, Z., \& Oleson, K. C. (1997). When exceptions prove the rule: how extremity of deviance determines the impact of deviant examples on stereotypes. Journal of Personality and Social Psychology, 72, 965-979. doi: 10.1037/0022-3514.72.5.965

Leyens, J. P., Demoulin, S., Vaes, J., Gaunt, R., \& Paladino, M. P. (2007). Infra-humanization: The wall of group differences. Social Issues and Policy Review, 1, 139-172. doi: 10.1111/j.17512409.2007.00006.x 
Leyens, J. P., Paladino, M. P., Rodriguez, R. T., Vaes, J., Demoulin, S., Rodriguez-Perez, A., \& Gaunt., R. (2000). The emotional side of prejudice: The role of secondary emotions. Personality and Social Psychology Review, 4, 186-197. doi:

10.1207/S15327957PSPR0402_06

Leyens, J. P., Rodriguez-Perez, A., Rodriguez-Torres, R., Gaunt, R., Paladino, M. P., Vaes, J., \& Demoulin, S. (2001). Psychological essentialism and the differential attribution of uniquely human emotions to ingroups and outgroups. European Journal of Social Psychology, 31, $395-411$.

McConnell, A. R., Sherman, S. J., \& Hamilton, D. L. (1994). Illusory correlation in the perception of groups: an extension of the distinctiveness-based account. Journal of personality and social psychology, 67, 414-429.

McKimmie, B. M., Masters, J. M., Masser, B. M., Schuller, R. A., \& Terry, D. J. (2013). Stereotypical and counterstereotypical defendants: Who is he and what was the case against her?. Psychology, Public Policy, and Law, 19, 343-354. doi: 10.1037/a0030505

Opotow, S. (1990). Moral exclusion and injustice: An introduction. Journal of Social Issues, 46, 120.

Paladino, M. P., \& Vaes, J. (2000). Humanity and valence of primary and secondary emotions. Unpublished raw data.

Preacher, K. J., \& Hayes, A. F. (2008). Asymptotic and resampling strategies for assessing and comparing indirect effects in multiple mediator models. Behavior Research Methods, 40, 879-891. doi: 10.3758/BRM.40.3.879

Roese, N. J., \& Sherman, J. W. (2007). Expectancy. Social psychology: Handbook of basic principles, 2, 91-115.

Sherman, J. W., \& Frost, L. A. (2000). On the encoding of stereotype-relevant information under cognitive load. Personality and Social Psychology Bulletin,26(1), 26-34. doi: $10.1177 / 0146167200261003$ 
Showers, C., \& Cantor, N. (1985). Social cognition: A look at motivated strategies. Annual Review of Psychology, 36, 275-305.

Stangor, C., Lynch, L., Duan, C., \& Glas, B. (1992). Categorization of individuals on the basis of multiple social features. Journal of Personality and Social Psychology, 62, 207-218.

Staub, E. (1989). The roots of evil: Psychological and cultural origins of genocide and other group violence. New York: Cambridge University Press.

Tadmor, C., Chao, M., Ying-yi Hong, \& Polzer, J. (2013). Not just for stereotyping anymore: Racial essentialism reduces domain-general creativity. Psychological Science, 24, 99-105. doi: $10.1177 / 0956797612452570$

Tadmor, C. T., Tetlock, P. E., \& Peng, K. (2009). Acculturation strategies and stereotype challenging complexity: The cognitive implications of biculturalism. Journal of CrossCultural Psychology, 40, 105-139. doi: 10.1177/0022022108326279

Tam, T., Hewstone, M., Cairns, E., Tausch, N., Maio, G., \& Kenworthy, J. (2007). The impact of intergroup emotions on forgiveness in Northern Ireland. Group Processes \& Intergroup Relations, 10, 119-136. doi: 10.1177/1368430207071345

Taylor, S. E., \& Gollwitzer, P. M. (1995). Effects of mindset on positive illusions. Journal of Personality and Social Psychology, 69, 213-226.

Tidball, M. E., Smith, D. G., Tidball, C. S., \& Wolf-Wendel, L. E. (1999). Taking Women Seriously: Lessons and Legacies for Educating the Majority. American Council on Education/Oryx Press Series on Higher Education. Oryx Press, PO Box 33889, Phoenix, AZ 85067-3889.

Tversky, A., \& Kahneman, D. (1974). Judgment under uncertainty: Heuristics and biases. Science, 185, 1124-1131.

Vasiljevic, M., \& Crisp, R. J. (2013). Tolerance by surprise: Evidence for a generalized reduction in prejudice and increased egalitarianism through novel category combination. PLOS ONE 8(3): e57106. doi:10.1371/journal.pone.0057106 
Weber, R., \& Crocker, J. (1983). Cognitive processes in the revision of stereotypic beliefs. Journal of Personality and Social Psychology, 45, 961-977. doi: 10.1037/0022-3514.45.5.961 


\section{Footnotes}

${ }^{1}$ Human nature traits attributed to each of the four outgroups (asylum seekers, elderly people, physical disabled people, homeless people) had a good internal reliability with a Cronbach's alpha respectively of $.66, .77, .73, .72$ thus were collapsed in four single indices. Similarly, uniquely human traits for each of the four outgroups had a good internal reliability with a Cronbach's alpha respectively of $.75, .77, .78, .84$ thus were collapsed in four single indices.

${ }^{2}$ Primary emotions attributed to each of the four outgroups (asylum seekers, learning disabled people, people with schizophrenia, homeless people) had a slightly good internal reliability with a Cronbach's alpha respectively of $.56, .53, .63, .65$ thus were collapsed in four single indices. Similarly, secondary emotions for each of the four outgroups had a good internal reliability with a Cronbach's alpha respectively of $.71, .78, .72, .72$ thus were collapsed in four single indices. 
Table 1: Correlations between Attributions of Human Nature (HN) and Human Uniqueness (HU) to thr four outgroups (Experiment 1).

\begin{tabular}{|c|c|c|c|c|c|c|c|c|}
\hline & 1. & 2. & 3. & 4. & 5. & 6. & 7. & 8. \\
\hline 1. Asylum seekers HN & -- & $.65 * *$ & $.60 * *$ & $.65 * *$ & $.46^{*}$ & $.30 *$ & .19 & $.33 * *$ \\
\hline 2. Elderly HN & & -- & $.64 * *$ & $.60 *$ & $.39 * *$ & $.35 * *$ & $.26^{*}$ & $.54 * *$ \\
\hline 3. Physically Disabled HN & & & -- & $.65^{* *}$ & $.58 * *$ & $.43 * *$ & $.49 * *$ & $.51 * *$ \\
\hline 4. Homeless HN & & & & -- & $.44 * *$ & $.29 *$ & $.24 *$ & $.52 *$ \\
\hline 5. Asylum seekers HU & & & & & -- & $.67 * *$ & $.62 * *$ & $.54 * *$ \\
\hline 6. Elderly HU & & & & & & -- & $.71 * *$ & $.64 * *$ \\
\hline 7. Physically Disabled HU & & & & & & & -- & $.60 * *$ \\
\hline 8. Homeless HU & & & & & & & & -- \\
\hline
\end{tabular}

Note. $* p<.05 ; * * p<.01 ; * * * p<.001$ 
Table 2: Attributions of Human Nature (HN) and Human Uniqueness (HU) as a function of combination type (Experiment 1).

\begin{tabular}{lcccc}
\hline & \multicolumn{4}{c}{ Combination Type } \\
& \multicolumn{2}{c}{ Stereotypic } & Counter-Stereotypic \\
Outgroups & $M$ & $S D$ & $M$ & $S D$ \\
& \multicolumn{5}{c}{ Human Nature } \\
& 3.89 & 0.73 & 4.27 & 0.55 \\
Asylum seekers & 4.00 & 0.80 & 4.39 & 0.74 \\
Elderly & 3.79 & 0.70 & 4.32 & 0.75 \\
Physically disabled & 3.85 & 0.76 & 4.22 & 0.82 \\
Homeless & \multicolumn{5}{c}{ Human Uniqueness } \\
\cline { 2 - 5 } & 3.42 & 0.67 & 4.37 & 0.78 \\
Asylum seekers & 3.49 & 0.91 & 4.34 & 0.79 \\
Elderly & 3.40 & 0.80 & 4.21 & 0.88 \\
Physically disabled & 3.52 & 0.91 & 4.37 & 0.86 \\
Homeless & & & \\
\hline
\end{tabular}


Table 3: Attributions of Primary and Secondary Emotions as a function of combination type (Experiment 2).

\begin{tabular}{|c|c|c|c|c|}
\hline \multirow[b]{3}{*}{ Outgroups } & \multicolumn{4}{|c|}{ Combination Type } \\
\hline & \multicolumn{2}{|c|}{ Stereotypic } & \multicolumn{2}{|c|}{ Counter-Stereotypic } \\
\hline & $M$ & $S D$ & $M$ & $S D$ \\
\hline & \multicolumn{4}{|c|}{ Primary Emotions } \\
\hline Asylum seekers & 4.28 & 0.76 & 4.00 & 0.67 \\
\hline Learning disabled & 4.41 & 0.72 & 3.89 & 0.62 \\
\hline $\begin{array}{l}\text { People with } \\
\text { schizophrenia }\end{array}$ & 4.36 & 0.71 & 4.27 & 0.70 \\
\hline \multirow[t]{2}{*}{ Homeless } & 4.22 & 0.72 & 4.39 & 0.66 \\
\hline & \multicolumn{4}{|c|}{ Secondary Emotions } \\
\hline Asylum seekers & 3.82 & 0.98 & 4.44 & 0.85 \\
\hline Learning disabled & 3.90 & 0.91 & 4.35 & 0.71 \\
\hline $\begin{array}{l}\text { People with } \\
\text { schizophrenia }\end{array}$ & 3.87 & 1.06 & 4.58 & 0.81 \\
\hline Homeless & 3.89 & 1.09 & 4.44 & 1.06 \\
\hline
\end{tabular}

